\title{
Planificación de comidas para la diabetes: manejo de la ingesta de carbohidratos ${ }^{1}$
}

Nancy J. Gal y Wendy J. Dahl; traducción por Daniela Rivero Mendoza. ${ }^{2}$

\section{Manejo de la ingesta de carbohidratos}

Mantener una ingesta constante de carbohidratos durante todo el día es un método eficaz de planificación de comidas para ayudar a mantener su objetivo de niveles de glucosa en sangre. Los alimentos que contienen carbohidratos tienen el mayor efecto sobre los niveles de glucosa en sangre en comparación con los alimentos que contienen principalmente proteínas o grasas. Los carbohidratos en los alimentos que contribuyen a la glucosa en la sangre incluyen azúcares y almidones. Los alimentos que contienen carbohidratos se dividen en grupos según su similar contenido de carbohidratos por porción. La cantidad de carbohidratos que consuma se basa en sus objetivos de tratamiento de la diabetes y la tolerancia a los carbohidratos.

Alimentos que contienen carbohidratos incluyen:

- Granos como panes, cereales, arroz, pasta

- Verduras con almidón como el maíz, la papa, la batata (camote), los guisantes y la calabaza (zapallo)

- Legumbres: guisantes secos y frijoles

- Leche y yogurt

- Frutas y jugos de frutas.

- Postres, dulces y bocadillos.
- Masas, empanizados, salsas dulces

Los alimentos que contienen pequeñas cantidades de carbohidratos incluyen:

- Verduras sin almidón como el brócoli, zanahorias, coliflor, judías verdes, verduras de hoja verde

- Nueces y semillas

Los alimentos que no contienen carbohidratos incluyen:

- Carnes, aves y mariscos (sin masas, empanizados o salsas dulces)

- Quesos añejos

- Aceites y grasas

\section{¿Cuáles son los beneficios de manejar los carbohidratos?}

- Permite flexibilidad en su plan de comidas.

- Ayuda a equilibrar sus alimentos y medicamentos.

- Ayuda a controlar las porciones de alimentos para mantener un peso saludable.

- Lo mantiene en control de sus niveles de glucosa en sangre.

1. Este documento, FSHN20-1s, es uno de una serie de publicaciones del Departamento de Ciencias de la Alimentación y Nutrición Humana, Servicio de Extensión Cooperativa de la Florida, Instituto de Alimentos y Ciencias Agrícolas, Universidad de la Florida (UF/IFAS Extension). Fecha de primera publicación: abril 2020. Visite nuestro sitio web EDIS en https://edis.ifas.ufl.edu.

2. Nancy J. Gal, Extension agent IV, food and consumer sciences, UF/IFAS Extension Marion County, Ocala, FL; and Wendy J. Dahl, associate professor, Food Science and Human Nutrition Department, UF/IFAS Extension, Gainesville, FL 32611. Traducción por Daniela Rivero Mendoza.

The Institute of Food and Agricultural Sciences (IFAS) is an Equal Opportunity Institution authorized to provide research, educational information and other services

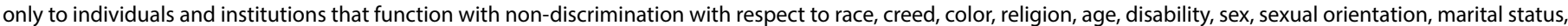

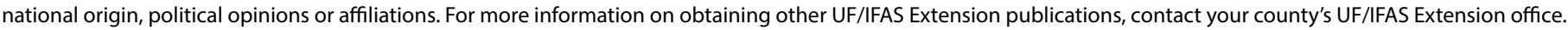
U.S. Department of Agriculture, UF/IFAS Extension Service, University of Florida, IFAS, Florida A \& M University Cooperative Extension Program, and Boards of County Commissioners Cooperating. Nick T. Place, dean for UF/IFAS Extension. 


\section{Preparando su plato-Manejando los carbohidratos}

Dentro de los grupos de alimentos con carbohidratos, cada opción contiene aproximadamente 15 gramos de carbohidratos y pueden intercambiarse entre sí, aunque los tamaños de las porciones varían. Por ejemplo, en el grupo de frutas, una porción de arándanos frescos es $3 / 4$ taza $o$ una porción de jugo de naranja es $1 / 2$ taza. En el grupo de almidones, una porción de arroz cocido es $1 / 3$ taza o $1 / 2$ taza de papas. En el grupo de la leche, una porción de leche es de 8 onzas y el yogur bajo en grasa es de $2 / 3$ de taza.

Tabla 1. Al planificar comidas y refrigerios, puede contar el número total de gramos de carbohidratos u opciones de carbohidratos.

\begin{tabular}{|l|c|c|}
\hline \multicolumn{1}{|c|}{$\begin{array}{c}\text { Grupo de alimentos con } \\
\text { carbohidratos } \\
\mathbf{1} \text { porción }\end{array}$} & $\begin{array}{c}\text { Gramos de } \\
\text { carbohidratos } \\
\text { (g) }\end{array}$ & $\begin{array}{c}\text { Opciones de } \\
\text { carbohidratos }\end{array}$ \\
\hline Almidones_granos & 15 & 1 \\
\hline Vegetales con almidón & 15 & 1 \\
\hline $\begin{array}{l}\text { Legumbres-guisantes secos } \\
\text { y frijoles }\end{array}$ & 15 & 1 \\
\hline Leche y yogurt & 12 & 1 \\
\hline Frutas y jugos de frutas & 15 & \\
\hline $\begin{array}{l}\text { Grupo de alimentos bajos en } \\
\text { carbohidratos }\end{array}$ & & 3 porciones = 1 \\
\hline Verduras sin almidón & 5 & \\
\hline
\end{tabular}

\section{Un ejemplo de menú de cena}

A continuación, se muestra un ejemplo de menú de cena basado en el Método del Plato para la Diabetes de la Asociación Americana de Diabetes. Para ver un video de demostración, consulte: https://www.youtube.com/ watch?v=A6LZijdsGu0.

Tabla 2. Ejemplo de menú.

\begin{tabular}{|c|c|}
\hline Grupo de alimento & Opción de alimento \\
\hline Almidón & papa pequeña al horno \\
\hline Proteina & 3 onzas de carne en rodajas \\
\hline Vegetales sin almidón & $\begin{array}{l}1 \frac{1}{2} \text { taza de verduras variadas: zanahorias, } \\
\text { brócoli y judías verdes }\end{array}$ \\
\hline Fruta & Manzana pequeña \\
\hline Leche o yogurt & $\begin{array}{l}3 / 4 \text { taza de leche de soya y } 1 / 4 \text { taza de } \\
\text { yogurt griego (aderezo para papa) }\end{array}$ \\
\hline
\end{tabular}

Dado que las necesidades dietéticas de cada persona son diferentes, es importante consultar con un Dietista Nutricionista Registrado (RDN), preferiblemente un educador certificado en diabetes (CDE), para determinar sus necesidades diarias de calorías y cuántas opciones de cada uno de los cinco grupos de alimentos necesita en cada comida y refrigerio (tentempié o merienda).
Asegúrese de consultar con su proveedor de atención médica antes de realizar cambios en su plan de tratamiento de la diabetes.

\section{Actividad: planificar un menú}

Planifique un menú de 1 día basándose en el Método de Plato de Diabetes de la Asociación Americana de Diabetes.

Use un plato de 9 pulgadas más un tazón pequeño y un vaso de bebida de $8 \mathrm{oz}$ para colocar los alimentos de cada uno de los cinco grupos de alimentos: proteínas magras, almidón, vegetales sin almidón, frutas y leche o yogurt.

Divida visualmente su plato en secciones para vegetales sin almidón, almidón y alimentos con proteínas magras (Imagen 1). Se pueden usar otros dos tazones o tazas pequeñas para la fruta, la leche o el yogur. $\mathrm{O}$ estos alimentos se pueden agregar a otros alimentos en el plato. La clave es seleccionar alimentos saludables de cada uno de los cinco grupos de alimentos para crear una comida saludable.

Imagen 1. Ejemplo del Método del Plato de Diabetes (salmón a la parrilla con mezcla de arroz basmati, brócoli y coles de Bruselas)

Tabla 3. Haciendo SU Menú.

\begin{tabular}{|l|l|}
\hline Desayuno & SU opción de alimento \\
\hline Grupo de alimento & \\
\hline Almidón & \\
\hline Proteina & \\
\hline Vegetales sin almidón & \\
\hline Fruta & \\
\hline Leche o yogurt & \\
\hline Almuerzo & SU opción de alimento \\
\hline Grupo de alimento & \\
\hline Almidón & \\
\hline Proteina & \\
\hline Vegetales sin almidón & \\
\hline Fruta & \\
\hline Leche o yogurt & \\
\hline Cena & \\
\hline Grupo de alimento & SU opción de alimento \\
\hline Almidón & \\
\hline Proteina & \\
\hline Vegetales sin almidón & \\
\hline Fruta & \\
\hline Leche o yogurt & \\
\hline
\end{tabular}

